\title{
Population, economic growth and regional environmental inefficiency: Evidence from U.S. states
}

\author{
George E. Halkos ${ }^{1 *}$, David I. Stern ${ }^{2}$, Nickolaos G. Tzeremes ${ }^{3}$ \\ ${ }^{1,3}$ Laboratory of Operations Research, Department of Economics, University of Thessaly, \\ Korai 43, 38333, Volos, Greece. \\ ${ }^{2}$ Crawford School of Public Policy, The Australian National University, 132 Lennox \\ Crossing, Acton, ACT 2601, Australia.
}

\begin{abstract}
We apply a conditional directional distance function allowing multiple exogenous factors to measure environmental performance. We evaluate the air pollution performance levels of U.S. states for the years 1998 and 2008. States' environmental inefficiency is determined by population size and GDP per capita (GDPPC). The overall results reveal that there is much variation in environmental inefficiencies among the U.S. states. A second stage nonparametric analysis indicates a nonlinear relationship between states' population size, GDPPC levels and states' environmental inefficiency levels. Our results indicate that environmental inefficiency on the whole decreases with increased population and income per capita but there are limits to this improvement and at high income and population levels the tendency may reverse.
\end{abstract}

Keywords: Regional environmental inefficiency; directional distance function; nonparametric regression; air pollution

\footnotetext{
*Corresponding author's E-mail: halkos@econ.uth.gr (Halkos, GE)
} 


\section{Introduction}

'Green growth', which tackles both environmental and development problems, is increasingly seen by policymakers (UNEP, 2009, 2011) as a way to address the perceived conflict (Isenhour and Feng, 2014; Jänicke, 2012) between environmental quality and economic development. In this approach, policymakers need to be able to evaluate the ability of an economy to shift towards more efficient and cleaner procedures and resource saving processes and products (Jänicke, 2012). As the OECD (2002) indicates, this can only be accomplished by evaluating the ability of the implemented policies of an economy or a region to break the link between environmental pressures and economic goods (known also as decoupling). As Wursthorn et al. (2011) show, decoupling indicators help the policymaker to measure the ability of an economy to expand without damaging the environment. Based on this framework, we develop environmental efficiency indicators that enable us to evaluate the ability of an economy or a region to decouple economic growth from environmental and ecological harm. As has been highlighted by Wang et al. (2013), we can have two kinds of decoupling - 'absolute' or 'relative'. Absolute decoupling occurs when economic growth results in stable or lower environmental pressures. Relative decoupling occurs when economic growth is associated with higher environmental pressures but the increase in economic output is significantly higher than the increase in environmental pressures in proportional terms so that the environmental intensity of output falls.

Environmental efficiency measures whether firms, regions, industries or other organizational units (called decision making units or DMUs) minimize emissions of pollutants given the available technology and the levels of other inputs such as capital and labor that they use (Huang et al., 2014; Wang et al., 2014; Wu et al., 2014). There are many studies that model environmental efficiency (e.g. Färe et al., 1989, 2006, 2007, 2010) but these studies generally do not attempt to account for exogenous factors (also known as 
environmental factors) that might explain the differences in efficiency across production or geographical units. Though the total level of pollution is the most relevant variable environmentally, in order to understand why pollution varies across countries and states we need to decompose the factors that drive pollution emissions (Stern, 2004). A key factor is environmental efficiency and its variation across regions.

In this paper, we apply a conditional directional distance function estimator in order to evaluate the effect of population size and GDP per capita (GDPPC) on U.S. states' environmental performance levels. We apply recent developments in conditional directional distance functions allowing that allow for multiple exogenous factors to determine technical efficiency under constant returns to scale (Daraio and Simar, 2014) to the environmental efficiency case.

There is some relevant related research on differences in environmental performance across U.S. states. Several studies have estimated environmental Kuznets curves for the states of the U.S.A. (Carson et al., 1997; List and Gallet, 1999; Aldy, 2005; Auffhammer and Steinhauser, 2012). Matisoff (2008) carried out an empirical analysis of the factors affecting the adoption of energy efficiency programs across U.S. states, Fredriksson and Millimet (2002) investigate whether states' environmental policy is influenced by their neighbors' policies and Heckman (2012) analyses the impact of management quality, spending, problem severity, and political factors on states' control of $\mathrm{NO}_{\mathrm{x}}$ emissions.

Färe et al. (1989) were the first to model the trade-off between environmental quality and economic development using a nonparametric distance function approach. They provide a framework for measuring environmental technology in a production function context that enables the development of environmental performance indicators. Their model treats pollutants as joint outputs of the production process and imposes strong and weak disposability conditions on inputs and outputs. Since then, several studies have tried to model 
the trade-off between economic growth and environmental quality using the distance function approach (among others Zaim and Taskin, 2000a, 2000b, 2000c; Taskin and Zaim, 2001; Zaim 2004; Managi, 2006; Yörük and Zaim, 2006; Managi and Jena, 2008). Most studies use country level data and normally involve the construction of measures of the environmental efficiency of the countries or regions first and then the effect of other variables on performance is assessed in a second stage regression type analysis.

However, as has been demonstrated by Simar and Wilson (2007, 2011), several unreasonable assumptions regarding the data generating process are needed in order for researchers to perform second-stage regressions using data envelopment analysis (hereafter DEA) efficiency scores as the dependent variable. In particular, most two-stage DEA studies assume that the separability condition between the input-output space and the space of the exogenous factors holds. Therefore, they assume that these factors (external/exogenous to the environmental production process) have no influence on the attainable set, affecting only the probability of being more or less efficient (Bădin et al., 2010, p.634). Finally, as reported by Daraio et al. (2010) the exogenous variables not only directly affect the shape of the distribution of the inefficiencies but also the production possibilities themselves.

Halkos and Tzeremes (2013a, 2013b) overcome these problems by applying the probabilistic characterization of directional distance functions firstly introduced by Simar and Vanhems (2012). ${ }^{1}$ In this paper, following the recent developments introduced by (Daraio and Simar, 2014) we apply a conditional directional distance function (CDDF) approach to the multivariate case measuring the effect of both GDP per capita and population levels on U.S. states' environmental inefficiency levels. The paper is organized as follows: section two presents the data and the methodology adopted whereas section three presents the results obtained. The final section presents some conclusions.

\footnotetext{
${ }^{1}$ By imposing the weak disposability assumption on the outputs Halkos and Tzeremes (2013a, 2013b) developed a conditional directional distance function estimator that models the environmental performance-economic growth relationship under constant and variable returns to scale.
} 


\section{Data and Methodology}

\subsection{Description of variables}

Following several other studies (Färe et al., 1989; Zaim and Taskin 2000a, 2000b, 2000c; Taskim and Zaim 2001; Färe and Grosskopf, 2004; Zaim, 2004; Yörük and Zaim, 2006; Halkos and Tzeremes, 2009), we use a set of inputs and a set of bad and good outputs in order to define U.S. states' environmental production process. We use data for all 50 states of the U.S.A. for 1998 and $2008 .^{2}$ The set of inputs used are capital stock (in millions of chained 2000 Dollars), energy use (in trillions of BTUs), and total state level employment. Furthermore, the good output is the real state GDP (in millions of 2005 Dollars) and the bad outputs are carbon monoxide (CO), mono-nitrogen oxides (NOx), and sulfur dioxide emissions $\left(\mathrm{SO}_{2}\right)$ measured in thousands of short tons. The variables we use to explain the inefficiency levels are states' population levels (obtained from ratio of total and per capita GDP) and GDP per capita levels in constant 2005 Dollars. We obtained data from several sources. States' total employment, real GDP and GDP per capita have been obtained from Bureau of Economic Analysis. ${ }^{3}$ Total primary energy use is from the State Energy Data System (SEDS) provided by U.S. Energy Information Administration. ${ }^{4}$ Data on air pollutants were obtained from the U.S. Environmental Protection Agency. ${ }^{5}$ Finally, estimates of states' capital stock levels were obtained from Garofalo and Yamarik (2002) and Yamarik (2013). Table 1 provides some descriptive statistics for the variables used in our analysis.

\section{Insert Table 1 about here}

\footnotetext{
${ }^{2}$ We do not include the District of Columbia in our dataset since it is regarded as outlier in our analysis.

${ }^{3}$ The data can be downloaded from: http://www.bea.gov/regional/.

${ }^{4}$ The data can be downloaded from: http://www.eia.gov/beta/state/seds/seds-data-complete.cfm?sid=US.

${ }^{5}$ The data can be downloaded from: http://www.epa.gov/ttn/chief/index.html.
} 


\subsection{Directional distance functions}

In an environmental production process (Färe et al., 1989, 2004; Chung et al., 1997) let the input vector denoted by $x \in \Re_{+}^{N}$ be able to produce both a set of undesirable $u \in \Re_{+}^{J}$ and desirable $v \in \Re_{+}^{M}$ outputs. Then following Shephard (1970) and Färe and Primont (1995) the environmental technology can be defined given the following assumptions. Specifically, we assume that the output sets are closed and bounded and that inputs are freely disposable. Additionally, the environmental output set $P(x)$ can only be defined if:

1. $(v, u) \in P(x)$ and $0 \leq \theta \leq 1$ then $(\theta v, \theta u) \in P(x)$ (i.e. the outputs are weakly disposable) and

2. $(v, u) \in P(x), u=0$ implies that $v=0$ (i.e. the null jointness assumption of good and bad outputs).

The assumption of weak disposability indicates that the reduction of bad outputs is costly and, therefore, it can only occur together with a simultaneous reduction in good outputs. Moreover, the assumption that the good outputs and bad outputs are null-joint implies that the bad outputs are by-products of the production process of good outputs.

Based on the weak disposability assumption for modeling undesirable outputs, a vast amount of research has been produced based on directional distance functions (among others Chung et al., 1997; Kuosmanen, 2005; Färe et al., 2006, 2007, 2010; Färe and Grosskopf, 2009; Kuosmanen and Podinovski, 2009). The environmental technology can be formalized via the DDF in a nonparametric setting with the use of DEA estimators ${ }^{6}$. Following many other studies (e.g. Chung et al., 1997; Macpherson et al., 2010; Picazo-Tadeo et al., 2005) we apply the DDF approach in order to measure states' environmental efficiency levels. More

\footnotetext{
${ }^{6}$ For some recent innovative applications of DEA measuring environmental efficiency and productivity see the studies by Fujii et al. (2011), Long et al. (2013), Chung and Heshmati (2014), Rashidi et al. (2014), Zhang (2014) and Bian et al. (2015).
} 
specifically, we apply a direction vector $g=\left(g_{v},-g_{u}\right)$ in order to be able to reduce bad and expand good outputs ${ }^{7}$. As a result, the environmental efficiency score for a state $k^{\prime}$ (for states $k=1, \ldots, K)$ can be obtained from:

$D\left(x^{k^{\prime}}, v^{k^{\prime}}, u^{k^{\prime}} ; g_{v}, g_{u}\right)=\max \beta$

s.t. $\left(v^{k^{\prime}}+\beta g_{v}, u^{k^{\prime}}-\beta g_{u}\right) \in P(x)$,

where $\omega_{k}, k=1, \ldots, K$ indicate the intensity variables, which are not negative and imply constant returns to scale. ${ }^{8}$ Environmental efficiency is indicated when $D\left(x^{k^{\prime}}, v^{k^{\prime}}, u^{k^{\prime}} ; g_{v}, g_{u}\right)=0$ and environmental inefficiency when $D\left(x^{k^{\prime}}, v^{k^{\prime}}, u^{k^{\prime}} ; g_{v}, g_{u}\right)>0$.

\subsection{Conditional directional distance functions}

The majority of nonparametric and parametric frontier studies impose some restrictive and unverifiable a priori assumptions (Simar and Wilson, 2007, 2011) in order to model the effect of the exogenous factors ${ }^{9}$ on the production process. By applying one-stage or two-stage approaches most of these studies are trying to capture the heterogeneity caused by the exogenous factors on the obtained efficiency scores by imposing several (usually) unrealistic assumptions. One of the main problems with the majority of two-stage DEA studies is the assumption of the 'separability condition' between the input-output space and the space of the exogenous factors. Under this condition those studies wrongly assume that the exogenous

\footnotetext{
${ }^{7}$ The directions chosen are based on the problem at hand and are left to the researcher to specify, however, the direction chosen for our analysis is common among the DEA based environmental performance studies.

${ }^{8}$ According to Picazo-Tadeo et al. (2012, p.802), the assumption of constant returns to scale (CRS) is most suitable when analyzing environmental problems. Moreover, Zelenyuk and Zelenyuk $(2014$, p.9) suggest that the CRS assumption allow us greater discriminative power over the variable returns to scale (VRS) assumption and, therefore, we are able to identify higher levels of inefficiency among the U.S. states. This is suitable in our case since we are able to better evaluate states' ability to decouple economic growth from environmental damage. Moreover, under the CRS assumption we are able to compare the U.S. states evenly to the estimated boundary serving as a natural benchmark for comparison of all states. This in turn is suitable for our second stage analysis since the effect of the exogenous factors will be revealed in emphatic manner in our second stage analysis. We acknowledge that states environmental inefficiency may occur due to scale effects, which are not captured under the CRS assumption. However, in our second stage analysis we partially tackle such effects by using sub-sample analysis based on states different GDPPC levels. For in depth analysis of this topic see Zelenyuk and Zheka (2006) and Shiu and Zelenyuk (2011).

${ }^{9}$ The exogenous factors, also called environmental factors, are all the factors that are not under the direct control of the decision maker and hence can influence the evaluated production process.
} 
factors have no influence on the attainable set, affecting only the probability of a decision making unit (DMU) being more or less efficient (Bădin et al., 2010, p.634).

This problem can be tackled by applying conditional efficiency measures ${ }^{10}$ based on the probabilistic formulation of the production process introduced by Daraio and Simar (2005). ${ }^{11}$ Recently, Simar and Vanhems (2012) introduced the probabilistic characterization of the directional distance functions for full and robust measures. ${ }^{12}$ Halkos and Tzeremes (2013a) conducted the first study applying the probabilistic characterization of the DDFs to the environmental problem by examining the influence of economic growth on UK regions' environmental performance. That study applies conditional DDFs where a single exogenous factor affects the environmental production process and assumes that there are constant returns to scale. ${ }^{13}$ In this paper, we extend the analysis to the multivariate case by examining how both states' GDP per capita and population levels affect their environmental performance in a DDF framework.

Following Daraio and Simar (2005) let the joint probability measure of $(X, V, U)$ and the joint probability function of $H_{X, V, U}(.,$.$) is defined as:$

$$
H_{X, V, U}(x, v, u)=\operatorname{Prob}(X \leq x, V \geq v, U \geq u) .
$$

Additionally, the following decomposition can be obtained as:

$$
H_{X, V, U}(x, v, u)=\operatorname{Prob}(V \geq v, U \geq u \mid X \leq x) \operatorname{Prob}(X \leq x)=S_{V, U \mid X}(v, u \mid x) F_{X}(x)
$$

where $F_{X}(x)=\operatorname{Prob}(X \leq x)$ and $S_{V, U \mid X}(v, u \mid x)=\operatorname{Prob}(V \geq v, U \geq u \mid X \leq x)$.

\footnotetext{
${ }^{10}$ For the theoretical background and the asymptotic properties of nonparametric conditional efficiency measures see Jeong et al. (2010).

${ }^{11}$ Daraio and Simar (2005) have extended the probabilistic characterization of the production process based on the work by Cazals et al. (2002).

${ }^{12}$ However, Daraio and Simar (2014), by extending the work of Bădin et al. (2012) are the first to develop the operational aspects for computing conditional and unconditional directional distances and their robust versions.

${ }^{13}$ For a conditional DDF measuring environmental performance under the assumption of variable returns to scale see Halkos and Tzeremes (2013b).
} 
Furthermore, let $Z \in R^{r}$ denote the exogenous factors influencing states' environmental production process (in our case these are states' GDP per capita (GDPPC) and population levels (POP)). Then equation (2) becomes:

$$
H_{X, V, U \mid Z}(x, v, u \mid z)=\operatorname{Prob}(X \leq x, V \geq v, U \geq u \mid Z=z)
$$

which and completely characterizes states' environmental production process. According to Daraio and Simar (2005) the following decomposition can be derived:

$$
\begin{aligned}
& H_{X, V, U \mid Z}(x, v, u \mid z)=\operatorname{Prob}(V \geq v, U \geq u \mid X \leq x, Z=z) \operatorname{Prob}(X \leq x \mid z) \\
& =S_{V, U \mid X, Z}(v, u \mid x, z) F_{X \mid Z}(x \mid z)
\end{aligned}
$$

The estimator of the conditional survival function introduced above can be obtained from:

$$
\hat{S}_{V, U \mid X, Z}(v, u \mid x, z)=\frac{\sum_{i=1}^{n} I\left(V_{i} \geq v, U_{i} \geq u, X_{i} \leq x\right) K\left(\left(Z_{i}-z\right) / h\right)}{\sum_{i=1}^{n} I\left(X_{i} \leq x\right) K\left(\left(Z_{i}-z\right) / h\right)}
$$

where $K($.$) is a kernel function defined on a compact support (Epanechnikov in our case)$ and $h$ is the appropriate bandwidth calculated following Bădin et al. (2010). ${ }^{14}$ However when $r>1$ ( as in our case $r=2$ ), and $Z=\left(Z^{1}, \ldots, Z^{r}\right)$ is multivariate, we follow Daraio and Simar (2014) and use a product kernel with a vector of bandwidths $h=\left(h_{1}, \ldots, h_{r}\right)$ and $K\left(\left(Z_{i}-z\right) / h\right)$ is the shortcut for $\prod_{l=1}^{r} K\left(\left(Z_{i}^{l}-z^{l}\right) / h_{l}\right)$

Recently, Simar and Vanhems (2012) developed the probabilistic characterization of the directional distance function taking the general form of:

$$
D\left(x, y ; g_{x}, g_{y}\right)=\sup \left\{\beta>0 \mid H_{X Y}\left(x-\beta g_{x}, y+\beta g_{y}\right)>0\right\},
$$

and the conditional directional distance function of $(x, y)$ conditional on $Z=z$ can then be defined as:

$$
D\left(x, y ; g_{x}, g_{y} \mid z\right)=\sup \left\{\beta>0 \mid H_{X Y \mid Z}\left(x-\beta g_{x}, y+\beta g_{y} \mid Z=z\right)>0\right\} .
$$

\footnotetext{
${ }^{14}$ The calculation of bandwidth by Bădin et al. (2010) is based on the Least Squares Cross Validation (LSCV) criterion introduced by Hall et al. (2004) and Li and Racine (2007).
} 
Following Halkos and Tzeremes (2013a), the probabilistic form of Färe and Grosskopf's (2004) model measuring environmental efficiency can be presented as:

$$
D\left(x^{k^{\prime}}, v^{k^{\prime}}, u^{k^{\prime}} ; g_{v}, g_{u}\right)=\sup \left\{\beta>0 \mid H_{X, V, U}\left(x^{k^{\prime}}, v^{k^{\prime}}+\beta g_{v}, u^{k^{\prime}}-\beta g_{u}\right)>0\right\}
$$

Then the conditional form of the model will take the form of ${ }^{15}$ :

$D\left(x^{k^{\prime}}, v^{k^{\prime}}, u^{k^{\prime}} ; g_{v}, g_{u} \mid z\right)=\sup \left\{\beta>0 \mid H_{X, V, U \mid Z}\left(x^{k^{\prime}}, v^{k^{\prime}}+\beta g_{v}, u^{k^{\prime}}-\beta g_{u} \mid Z=z\right)>0\right\}$.

As noted previously, efficient states will be indicated when $D\left(x^{k^{\prime}}, v^{k^{\prime}}, u^{k^{\prime}}, g_{v}, g_{u} \mid z\right)=0$ and inefficient states will be indicated by values of $D\left(x^{k^{\prime}}, v^{k^{\prime}}, u^{k^{\prime}} ; g_{v}, g_{u} \mid z\right)>0$.

The direction function in (10) is able to account directly for the effects of states' GDPPC and population levels on their environmental performance. Therefore, the environmental inefficiency estimates obtained are determined by the inputs, the good and bad outputs, and both of the two exogenous factors. Finally, we do not impose in our analysis the restrictive separability assumption between states' environmental performance and the exogenous variables (Simar and Wilson, 2007, 2011).

\subsection{Determining the effect of states' economic growth and population levels}

Using recent developments in computing conditional and unconditional directional distances and their robust versions (Daraio and Simar, 2014), we can identify the effects of the exogenous variables (GDPPC and POP) on states' environmental inefficiency levels. According to Daraio and Simar (2014), when using radial oriented measures (as in our case) we explore a potential shift of the estimated frontier as a function of the exogenous factors. But when using the robust version of the DDF we can also explore the potential shift of the distribution of the inefficiencies as a function of the exogenous factors. ${ }^{16}$ As has been

\footnotetext{
${ }^{15}$ For the computational aspects of conditional directional distance functions see Daraio and Simar (2014).

${ }^{16}$ The construction of an estimator measuring environmental inefficiency levels in an output oriented framework when using robust measures and under the weak disposability assumption of bad outputs is not in the scope of our study and is left for future research.
} 
emphasized by De Witte and Marques (2010) outliers can influence the efficiency estimates of the conditional directional distance functions. In our analysis, the only potential outlier was the District of Columbia and we intentionally excluded it from our analysis. ${ }^{17}$ These can be derived if we examine the ratios of conditional to unconditional state environmental inefficiency measures:

$$
\hat{Q}=\frac{\left(1+\hat{D}\left(x^{k^{\prime}}, v^{k^{\prime}}, u^{k^{\prime}} ; g_{v}, g_{u} \mid z\right)\right)}{\left(1+\hat{D}\left(x^{k^{\prime}}, v^{k^{\prime}}, u^{k^{\prime}} ; g_{v}, g_{u}\right)\right)} \text {. }
$$

We assume that the vector $z$ consists of income per capita and the population level. For this purpose we use the local linear estimator (Fan, 1992, 1993) in order to regress states' ratios of the conditional to unconditional environmental inefficiency estimates on their income per capita and population levels. In our case (an output oriented DDF), an increasing nonparametric regression line will indicate a favorable effect of states' economic growth and population levels on their environmental inefficiency. In the opposite way a decreasing nonparametric line will indicate an unfavorable effect. ${ }^{18}$

\section{Empirical results}

Table 2 presents our estimates of U.S. states' environmental inefficiency levels (SEI) for the two examined periods. ${ }^{19}$ For the original inefficiency estimates and for the year 1998 twenty-two states are reported to be environmental efficient (i.e. SEI score equals to 0). The environmental efficiency score reflects a state's ability to maximize good outputs and simultaneously minimize bad outputs given input quantities. Therefore, an environmentally

\footnotetext{
${ }^{17}$ De Witte and Marques (2010) have developed non-oriented robust conditional directional distance functions under the free disposability assumption with the inclusion of bad outputs that allow the examination of the effect of outliers on the efficiency estimates (see also Wilson, 1995; Baležentis and De Witte, 2015 inter alia). In our modeling setting we initially identified the District of Columbia acts as an outlier and we excluded it from our analysis. However, since we compare the U.S. states, any further exclusions of our states will weaken our ability to evaluate the other states' decoupling ability and will lead to biased results.

${ }^{18}$ This is the standard approach used to investigate the global effect of the exogenous factors on the estimated efficiency levels and is well documented in the relative literature (Daraio and Simar, 2005; Bădin et al., 2010; Daraio and Simar, 2014).

${ }^{19}$ Table 2 presents also the conditional estimates SEI|z for 1998 and 2008. However since these inefficiency estimates include the effect of regions' GDPPC and population level they are not meaningful for ranking purposes.
} 
efficient state is one that maximizes its GDP and simultaneously minimizes its CO, NOx, and $\mathrm{SO}_{2}$ levels given its capital stock, energy use, and employment levels.

Specifically, for the year 2008, twenty-three states are reported to be environmentally efficient. From 1998 to 2008, Table 2 shows that seventeen states increased their environmental performance, nineteen decreased their environmental performance and fourteen remained unchanged. Fourteen states are found to be environmental efficient states (i.e. environmental inefficiency equals 0 ) in both examined years. These states are Alaska, California, Connecticut, Delaware, Hawaii, New Jersey, New York, North Dakota, Oregon, Rhode Island, South Dakota, Utah, West Virginia and Wyoming.

On average (i.e. the average SEI for the two periods), the twenty-six states with the highest environmental performance (with average SEI score $<0.1$ ) are Alaska, California, Connecticut, Delaware, Hawaii, New Jersey, New York, North Dakota, Oregon, Rhode Island, South Dakota, Utah, West Virginia, Wyoming, Massachusetts, New Mexico, New Hampshire, Virginia, Nevada, Maryland, Washington, Arizona, Nebraska, Vermont, Colorado and North Carolina. The twenty-four states with the lowest performances (with average SEI score $\geq 0.1$ ) are Pennsylvania, Illinois, Florida, Maine, Minnesota, Mississippi, Ohio, Idaho, Louisiana, Kansas, South Carolina, Montana, Iowa, Alabama, Arkansas, Wisconsin, Texas, Georgia, Missouri, Tennessee, Indiana, Kentucky, Michigan and Oklahoma. Finally, the descriptive statistics of the conditional environmental inefficiency estimates reveal that on average SEI levels increase when we account both for the effect of states' GDPPC and population levels. This in turn is a first indication that higher population levels and GDPPC levels tend to decrease the ability of the U.S. states to decouple economic growth from environmental damage. 
Figure 1 presents the kernel density functions of the conditional and unconditional SEI scores. For the calculation of the density estimates we have applied for bandwidth selection the "rule-of-thumb" (Silverman, 1986) and a second order Gaussian kernel. Sub-figure 1a and $1 \mathrm{~b}$ illustrate the distribution of the unconditional and conditional environmental inefficiency estimates for 1998 and 2008, respectively. As can be seen, in both years the distribution of the conditional estimates is platykurtic. As a result, states' environmental inefficiency estimates are highly dispersed and their distribution is less clustered around the mean than in a leptokurtic distribution. For the case of unconditional estimates a twin peak distribution is revealed both for 1998 and 2008. More specifically, a bimodal distribution is revealed. For 1998 , there is one group of states with SEI levels of around 0 and another of 0.25 . Moreover, in 2008 there is a twin-peaked distribution around SEI levels of 0 and 0.35 . Clearly, this result complements the analytical findings presented previously indicating that there are two dominant groups of states with high and low SEI levels.

\section{Insert Figure 1 about here}

Furthermore we can investigate the potential effects of the conditioning variables (GDPPC and POP in our case) on the shift of the frontier. As explained previously, this can be obtained by considering the ratios of the conditional to unconditional directional distance inefficiency measures $(\hat{Q})$. If the ratio increases with the conditioning variables then there is a favorable effect and vice versa. Figure 2 illustrates the combined effect of states' GDP per capita and population levels on states' environmental inefficiencies in 3-dimentional graphs. Specifically, sub-figure $2 \mathrm{a}$ presents the combined effect of the conditioning variables for 1998. As can be observed, the effect of population on states' environmental inefficiency levels has a nonlinear form indicating that for lower population levels states' environmental inefficiency levels tend to decrease up to certain population level, whereas after that level states' environmental inefficiencies levels tend to increase. Furthermore the results reveal a 
'U'-shape relationship between GDPPC and states' environmental inefficiency levels. This suggests that states' inefficiency levels tend to decrease when GDPPC increases up to a certain level, which after that level states' inefficiency levels tend to increase. However, the highest inefficiencies are in small and poor states as GDP per capita and population increase there is a degree of decoupling but this disappears at the highest income and population levels. Similar results are also revealed for 2008 (sub-Figure 2b), indicating a 'U'-shape form both with GDPPC and population levels with SEI. However, decoupling with growth in GDP per capita seems to be less important in 2008 and the main effect is reduced inefficiency with higher population. Finally, subfigure $2 \mathrm{c}$ provides the analysis when we consider the dataset for 1998 and 2008 jointly. The results reveal that when states' GDPPC and population levels increase SEI levels decrease. However, states with high populations have lower SEI levels irrespective of income..

\section{Conclusions}

Decoupling implies the ability of an economy to increase its economic output without damaging its environment due to the production of pollutants (Wang et al., 2013). From that perspective there is a need for indicators that measure this decoupling ability is needed in order to evaluate the ability of an economy to break the link between environmental damage and economic performance. The environmental inefficiency indicator developed in this paper - SEI - is an indicator of relative decoupling which measures the tendency for environmental intensity of output to increase or decrease with growth in income and population.

In order to assess the tendency for relative decoupling in US states we model U.S. states' environmental efficiency as a function of their GDP per capita and population levels. Using a probabilistic characterization (Simar and Vanhems, 2012) and additional operational aspects (Daraio and Simar, 2014) of DDFs, we imposed weak disposability of outputs on the 
conditional directional distance functions by extending to the multivariate case the environmental performance estimator proposed by Halkos and Tzeremes (2013a). Specifically, we investigated for the years 1998 and 2008 the effect of GDP per capita and population on U.S. states' environmental inefficiency levels under the assumption of constant returns to scale. The results reveal that mostly environmental inefficiency declines with increased income per capita and population but there are limits to these tendencies at high income and population levels. In particular, small poor states tend to be environmentally inefficient, whereas large states tend to be more efficiency regardless of their level of income. Our results complement the findings of Halkos and Tzeremes (2013a, 2013b) who investigated the effect of GDP per capita for the U.K. and U.S. states.

The results show that there is not so much of a trade off between environmental quality and economic development in small and poor US states in the South and MidWest. As these states grow in income and population they can improve their environmental efficiency. However, large and richer states face more environmental challenges from growth. This may explain the differences in policy across states. For example, California which is already an environmentally efficient state is also a state which has lead in environmental regulation. There are fewer local environmental policies in states across the South and parts of the midWest (Matisoff, 2008). Politicians and populations in these states may see less trade off between environmental quality and development and hence be reluctant to adopt specific environmental policies. These pattern also match recent trends in voting for the Republican and Democratic parties the so-called Blue and Red States. However, there are exceptions to a simplistic analysis along these lines as Texas for example is an environmentally efficient states in our analysis as would be expected from its large population size.

\section{Acknowledgements}


We would like to thank two anonymous reviewers for the comments provided in relation to an earlier version of our paper. Any remaining errors are solely the authors' responsibility. 


\section{References}

Aldy, J. E., 2005. An environmental Kuznets curve analysis of U.S. state-level carbon dioxide emissions. J. Environ. Dev. 14(1), 48-72.

Auffhammer, M., Steinhauser, R., 2012. Forecasting the path of U.S. CO2 emissions using state-level information. Rev. Econ. Stat. 94(1), 172-185.

Bădin, L., Daraio, C., Simar, L., 2010. Optimal bandwidth selection for conditional efficiency measures: a data-driven approach. Eur. J. Oper. Res. 201(2), 633-640.

Baležentis, T., De Witte, K., 2015. One-and multi-directional conditional efficiency measurement-Efficiency in Lithuanian family farms. Eur. J. Oper. Res. http://dx.doi.org/10.1016/j.ejor.2015.01.050.

Bian, Y., Liang, N., Xu, H., 2015. Efficiency evaluation of Chinese regional industrial systems with undesirable factors using a two-stage slacks-based measure approach. J. Clean. Prod. 87, 348-356.

Carson, R.T., Jeon, Y., McCubbin, D.R., 1997. The relationship between air pollution emissions and income: U.S. data. Environ. Dev. Econ. 2(4), 433-450.

Cazals, C., Florens, J.P., Simar, L., 2002. Nonparametric frontier estimation: a robust approach. J. Econometrics. 106(1), 1-25.

Chung, Y., Heshmati, A., 2014. Measurement of environmentally sensitive productivity growth in $\quad$ Korean industries. J. Clean. Prod. http://dx.doi.org/10.1016/j.jclepro.2014.06.030.

Chung, Y.H., Färe, R., Grosskopf, S., 1997. Productivity and undesirable outputs: a directional distance function approach. J. Environ. Manage. 51(3), 229-240.

Daraio, C., Simar, L., 2005. Introducing environmental variables in nonparametric frontier models: a probabilistic approach. J. Prod. Anal. 24(1), 93-121. 
Daraio, C., Simar, L., 2014. Directional distances and their robust versions: Computational and testing issues. Eur. J. Oper. Res. 237(1), 358-369.

Daraio, C., Simar, L., Wilson, P., 2010. Testing whether two-stage estimation is meaningful in non-parametric models of production, Discussion Paper 1031, Institut de Statistique, UCL, Belgium.

De Witte, K., Marques, R.C., 2010. Influential observations in frontier models, a robust nonoriented approach to the water sector. Ann Oper Res 181, 377-392.

Fan, J., 1992. Design-adaptive nonparametric regression. J. Am. Stat. Assoc. 87(420), 9981004.

Fan, J., 1993. Local linear smoothers and their minimax efficiency. Ann. Stat. 21(1), 196-216.

Färe, R., Grosskopf, S., 2004. Modeling undesirable factors in efficiency evaluation: Comment. Eur. J. Oper. Res. 157(1), 242-245.

Färe, R., Grosskopf, S., 2009. A comment on weak disposability in production analysis. Am. J. Agr. Econ. 91(2), 535-538.

Färe, R., Grosskopf, S., Hernandez-Sancho, F., 2004. Environmental performance: an index number approach. Resour. Energy. Econ. 26(4), 343-352.

Färe, R., Grosskopf, S., Lovell, C.A.K., Pasurka, C., 1989. Multilateral productivity comparisons when some outputs are undesirable: a nonparametric approach. Rev. Econ. Stat. 71(1), 90-98.

Färe, R., Grosskopf, S., Pasurka, C.A., 2006. Social responsibility: U.S. power plants 19851998. J. Prod. Anal. 26(3), 259-267.

Färe, R., Grosskopf, S., Pasurka, C.A., 2007. Pollution abatement activities and traditional productivity. Ecol. Econ. 62(3-4), 673-682.

Färe, R., Grosskopf, S., Pasurka, C.A., 2010. Toxic releases: an environmental performance index for coal-fired power plants. Energ. Econ. 32(1), 158-165. 
Färe, R., Primont, D., 1995. Multi-Output Production and Duality: Theory and Applications, Kluwer Academic Publishers, Boston.

Fredriksson, P.G., Millimet D.L., 2002. Strategic interaction and the determination of environmental policy across U.S. States. J. Urban Econ. 51(1), 101-122.

Fujii, H., Managi, S., Kawahara, H., 2011. The pollution release and transfer register system in the U.S. and Japan: an analysis of productivity. J. Clean. Prod. 19, 1330-1338.

Garofalo, G. A., Yamarik, S., 2002. Regional convergence: evidence from a new state-bystate capital stock series. Rev. Econ. Stat. 84(2), 316-323.

Halkos, G.E., Tzeremes, N.G., (2013a). A conditional directional distance function approach for measuring regional environmental efficiency: Evidence from UK regions. Eur. J. Oper. Res. 227(1), 182-189.

Halkos, G.E., Tzeremes, N.G., 2009. Exploring the existence of Kuznets curve in countries' environmental efficiency using DEA window analysis. Ecol. Econ. 68(7), 2168-2176.

Halkos, G.E., Tzeremes, N.G., 2013b. Economic growth and environmental efficiency: Evidence from U.S. regions. Econ. Lett. 120(1), 48-52.

Hall, P., Racine, J.S., Li, Q., 2004. Cross-validation and the estimation of conditional probability densities. J. Am. Stat. Assoc. 99(468), 1015-1026.

Heckman, A. C., 2012. Desperately seeking management: Understanding management quality and its impact on government performance outcomes under the Clean Air Act. J. Publ. Adm. Res. Theor. 22(3), 473-496.

Huang, J., Yang, X., Cheng, G., Wang, S., 2014. A comprehensive eco-efficiency model and dynamics of regional eco-efficiency in China. J. Clean. Prod. 67, 228-238.

Isenhour, C., Feng, K., 2014. Decoupling and displaced emissions: on Swedish consumers, Chinese producers and policy to address the climate impact of consumption. J. Clean. Prod. dx.doi.org/10.1016/j.jclepro.2014.12.037. 
Jänicke, M., 2012. Green growth: From a growing eco-industry to economic sustainability. Energ. Policy. 48, 13-21.

Jeong, S.O., Park, B.U., Simar, L., 2010. Nonparametric conditional efficiency measures: asymptotic properties. Ann. Oper. Res. 173(1), 105-122.

Kuosmanen, T., 2005. Weak disposability in nonparametric productivity analysis with undesirable outputs. Am. J. Agr. Econ. 87(4), 1077-1082.

Kuosmanen, T., Podinovski, V.V., 2009. Weak disposability in nonparametric production analysis: Reply to Färe and Grosskopf. Am. J. Agr. Econ. 91(2), 539-545.

Li, Q., Racine, J.S., 2007. Nonparametric econometrics: Theory and practice, Princeton University Press, Oxford.

List, J. A., Gallet, C.A., 1999. The environmental Kuznets curve: does one size fit all? Ecol. Econ. 31(3), 409-423.

Long, X., Oh, K., Cheng, G., 2013. Are stronger environmental regulations effective in practice? The case of China's accession to the WTO. J. Clean. Prod. 39, 161-167.

Lu, Z., Wang, H., Yue, Q. 2014., Decoupling analysis of the environmental mountain: with case studies from China. J. Indu. Ecol. doi:10.1111/jiec.12226.

Macpherson, A.J., Principe, P.P., Smith, E.R., 2010. A directional distance function approach to regional environmental-economic assessments. Ecol. Econ. 69(10), 1918-1925.

Managi, S., 2006. Are there increasing returns to pollution abatement? Empirical analytics of the Environmental Kuznets Curve in pesticides. Ecol. Econ. 58(3), 617-636.

Managi, S., Jena, P.R., 2008. Environmental productivity and Kuznets curve in India. Ecol. Econ. 65(2), 432-440.

Matisoff, D.C., 2008. The adoption of state climate change policies and renewable portfolio standards: regional diffusion or internal determinants? Rev. Pol. Res. 25(6), 527-546. 
OECD. 2002. Indicators to measure decoupling of environmental pressure from economic growth. Organization for Economic Co-operation and Development. Paris, France.

Picazo-Tadeo, A.J., Beltrá-Esteve, M., Gómez-Limón, J.A., 2012. Assessing eco-efficiency with directional distance functions. Eur. J. Oper. Res., 220(3), 798-809.

Picazo-Tadeo, A.J., Reig-Martínez, E., Hernández-Sancho, F., 2005. Directional distance functions and environmental regulation. Resour. Energy. Econ. 27(2), 131-142.

Rashidi, K., Shabani, A., Saen, R. F., 2014. Using data envelopment analysis for estimating energy saving and undesirable output abatement: a case study in the Organization for Economic Co-Operation and Development (OECD) countries. J. Clean. Prod. http://dx.doi.org/10.1016/j.jclepro.2014.07.083.

Shephard, R.W., 1970. Theory of Cost and Production Functions, Princeton University Press, Princeton, NJ.

Shiu, A., Zelenyuk, V. (2011). Production efficiency versus ownership: The case of China. In Ingrid Van Keilegom and Paul W. Wilson (Ed.), Exploring research frontiers in contemporary statistics and econometrics (pp. 23 - 44) Heidelberg, Germany: Springer.

Silverman, B.W., 1986. Density Estimation for Statistics and Data Analysis, Chapman and Hall, London.

Simar, L., Vanhems, A., 2012. Probabilistic characterization of directional distances and their robust versions. J. Econometrics. 166(2), 342-354.

Simar, L., Wilson, P.W., 2007. Estimation and inference in two-stage, semi-parametric models of production processes. J. Econometrics. 136(1), 31-64.

Simar, L., Wilson, P.W., 2011. Two-stage DEA: caveat emptor. J. Prod. Anal. 36(2), 205218

Stern, D.I., 2004. The rise and fall of the environmental Kuznets curve. World. Dev. 32(8), $1419-1439$. 
Taskin, F., Zaim, O., 2001. The role of international trade on environmental efficiency: A DEA approach. Econ. Model. 18(1), 1-17.

UNEP. 2009. Global green new deal: Policy brief. United Nations Environment Programme, Economics and Trade Branch. Geneva, Switzerland.

UNEP. 2011. Towards a green economy: Pathways to sustainable development and poverty eradication. United Nations Environment Programme. Nairobi, Kenya.

Wang, H., Hashimoto, S., Yue, Q., Moriguchi, Y., Lu, Z., 2013. Decoupling analysis of four selected countries: China, Russia, Japan, and the United States during 2000-2007. J. Indu. Ecol. 17, 618-629.

Wang, W.K., Lu, W.M., Wang, S.W., 2014. The impact of environmental expenditures on performance in the U.S. chemical industry. J. Clean. Prod. 64, 447-456.

Wilson, P. 1995. Detecting influential observations in data envelopment analysis. J. Prod. Anal. 6, 27-45.

Wu, J., An, Q., Yao, X., Wang, B., 2014. Environmental efficiency evaluation of industry in China based on a new fixed sum undesirable output data envelopment analysis. J. Clean. Prod. 74, 96-104.

Wursthorn, S., Poganietz, W-R., Schebek., L., 2011. Economic-environmental monitoring indicators for European countries: A disaggregated sector-based approach for monitoring eco-efficiency. Ecol. Econ. 70, 487-496.

Yamarik, S., 2013. State-level capital and investment: updates and implications. Contemp. Econ. Policy, 31(1), 62-72.

Yörük, B.K., Zaim, O., 2006. The Kuznets curve and the effect of international regulations on environmental efficiency. Econ. Bull. 17(1), 1-7.

Zaim, O., 2004. Measuring environmental performance of state manufacturing through changes in pollution intensities: a DEA framework. Ecol. Econ. 48(1), 37- 47. 
Zaim, O., Taskin, F., 2000a. Environmental efficiency in carbon dioxide emissions in the OECD: A non-parametric approach. J. Environ. Manage. 58(2), 95-107.

Zaim, O., Taskin, F., 2000b. Searching for a Kuznets curve in environmental efficiency using kernel estimation. Econ. Lett. 68(2), 217-223.

Zaim, O., Taskin, F., 2000c. A Kuznets curve in environmental efficiency: an application on OECD countries. Environ. Res. Econ. 17(1), 21-36.

Zelenyuk, N., Zelenyuk, V. 2014. Regional and ownership drivers of bank efficiency. CEPA working paper No. WP11/2014, Centre for Efficiency and Productivity Analysis (CEPA), School of Economics University of Queensland, Australia.

Zelenyuk, V., Zheka, V., 2006. Corporate governance and firm's efficiency: The case of a transitional country, Ukraine. J. Prod. Anal. 25, 143-168.

Zhang, S., 2014. Evaluating the method of total factor productivity growth and analysis of its influencing factors during the economic transitional period in China. J. Clean. Prod., http://dx.doi.org/10.1016/j.jclepro.2014.09.097. 
Table 1: Descriptive statistics of the variables

\begin{tabular}{|c|c|c|c|c|c|c|c|c|c|}
\hline $\begin{array}{l}\text { Year } \\
1998 \\
\end{array}$ & $\begin{array}{c}\text { Total } \\
\text { Employment } \\
\end{array}$ & $\begin{array}{c}\text { Energy } \\
\text { (Trillion } \\
\text { BTU) } \\
\end{array}$ & $\begin{array}{c}\text { Capital } \\
\text { Stock } \\
(\text { Bil. 2005 \$) } \\
\end{array}$ & $\begin{array}{c}\text { GDP } \\
\text { (Bil. 2005 \$) } \\
\end{array}$ & $\begin{array}{c}\text { CO } \\
\text { (Thou. ST) } \\
\end{array}$ & $\begin{array}{c}\text { NOx } \\
\text { (Thou. ST) } \\
\end{array}$ & $\begin{array}{c}\text { SO }_{2} \\
\text { (Thou. ST) } \\
\end{array}$ & $\begin{array}{c}\text { GDP per } \\
\text { capita } \\
(2005 \$) \\
\end{array}$ & Population \\
\hline Mean & $3,155,576$ & 1,896 & 190,170 & 204,406 & 1,787 & 488 & 392 & 36,133 & $5,508,867$ \\
\hline$S t d$ & $3,346,326$ & 2,110 & 232,276 & 236,415 & 1,539 & 404 & 410 & 6,704 & $6,043,366$ \\
\hline Min & 313,121 & 136 & 18,071 & 18,086 & 216 & 35 & 12 & 25,806 & 491,654 \\
\hline $\operatorname{Max}$ & $18,370,580$ & 12,469 & $1,210,298$ & $1,270,101$ & 8,072 & 2,140 & 1,921 & 56,896 & $33,029,959$ \\
\hline $\begin{array}{l}\text { Year } \\
2008 \\
\end{array}$ & $\begin{array}{c}\text { Total } \\
\text { Employment } \\
\end{array}$ & $\begin{array}{c}\text { Energy } \\
\text { (Trillion } \\
\text { BTU) } \\
\end{array}$ & $\begin{array}{c}\text { Capital } \\
\text { Stock } \\
\text { (Bil. 2005 \$) } \\
\end{array}$ & $\begin{array}{c}\text { GDP } \\
\text { (Bil. 2005 \$) } \\
\end{array}$ & $\begin{array}{c}\text { CO } \\
\text { (Thou. ST) }\end{array}$ & $\begin{array}{c}\text { NOx } \\
\text { (Thou. ST) } \\
\end{array}$ & $\begin{array}{c}\mathrm{SO}_{2} \\
\text { (Thou. ST) } \\
\end{array}$ & $\begin{array}{c}\text { GDP per } \\
\text { capita } \\
(2005 \$) \\
\end{array}$ & Population \\
\hline Mean & $3,576,691$ & 1,980 & 235,690 & 258,570 & 1,644 & 343 & 207 & 41,897 & $6,034,151$ \\
\hline Std & $3,837,979$ & 2,034 & 302,948 & 313,039 & 1,715 & 295 & 230 & 7,731 & $6,686,673$ \\
\hline Min & 399,767 & 149 & 21,045 & 22,772 & 146 & 21 & 4 & 28,454 & 544,913 \\
\hline $\operatorname{Max}$ & $20,706,409$ & 11,514 & $1,562,427$ & $1,756,115$ & 10,513 & 1613 & 990 & 61,460 & $36,389,378$ \\
\hline
\end{tabular}

Table 2: Estimates of states' environmental inefficiency scores

\begin{tabular}{|c|c|c|c|c|c|c|c|c|c|}
\hline States & SEI $_{1998}$ & $\mathbf{S E I}_{2008}$ & SEI $\mid z, 1998$ & SEI $\mid \mathbf{z}, 2008$ & States & SEI $_{1998}$ & SEI $_{2008}$ & SEI $\mid z, 1998$ & SEI $\mid \mathbf{z}, 2008$ \\
\hline Alabama & 0.3611 & 0.0841 & 0.8257 & 0.5369 & New Hampshire & 0.0000 & 0.0387 & 0.0000 & 0.1315 \\
\hline Alaska & 0.0000 & 0.0000 & 0.0000 & 0.0000 & New Jersey & 0.0000 & 0.0000 & 0.0945 & 0.0000 \\
\hline Arizona & 0.0731 & 0.0372 & 0.0000 & 0.1830 & New Mexico & 0.0030 & 0.0000 & 0.6239 & 0.0000 \\
\hline Arkansas & 0.1833 & 0.2776 & 0.8856 & 0.6376 & New York & 0.0000 & 0.0000 & 0.0000 & 0.0000 \\
\hline California & 0.0000 & 0.0000 & 0.0000 & 0.0000 & North Carolina & 0.1848 & 0.0000 & 0.0000 & 0.0000 \\
\hline Colorado & 0.0000 & 0.1524 & 0.0054 & 0.1927 & North Dakota & 0.0000 & 0.0000 & 0.6291 & 0.0000 \\
\hline Connecticut & 0.0000 & 0.0000 & 0.4150 & 0.0000 & Ohio & 0.0000 & 0.2862 & 0.0000 & 0.1741 \\
\hline Delaware & 0.0000 & 0.0000 & 0.5234 & 0.0000 & Oklahoma & 0.2999 & 0.4618 & 0.8057 & 0.5030 \\
\hline Florida & 0.1466 & 0.0893 & 0.0000 & 0.0000 & Oregon & 0.0000 & 0.0000 & 0.7524 & 0.0000 \\
\hline Georgia & 0.2643 & 0.3151 & 0.0000 & 0.1716 & Pennsylvania & 0.2004 & 0.0000 & 0.0000 & 0.0000 \\
\hline Hawaii & 0.0000 & 0.0000 & 0.1874 & 0.0230 & Rhode Island & 0.0000 & 0.0000 & 0.2119 & 0.0000 \\
\hline Idaho & 0.3012 & 0.0000 & 0.8904 & 0.3676 & South Carolina & 0.1569 & 0.2186 & 0.6075 & 0.4417 \\
\hline Illinois & 0.1161 & 0.0947 & 0.0000 & 0.0000 & South Dakota & 0.0000 & 0.0000 & 0.6357 & 0.2597 \\
\hline Indiana & 0.3414 & 0.2797 & 0.1636 & 0.2618 & Tennessee & 0.2858 & 0.3245 & 0.4625 & 0.3853 \\
\hline Iowa & 0.2250 & 0.2092 & 0.3426 & 0.3198 & Texas & 0.4254 & 0.1118 & 0.0000 & 0.0000 \\
\hline Kansas & 0.0000 & 0.3221 & 0.0000 & 0.4729 & Utah & 0.0000 & 0.0000 & 0.3950 & 0.0000 \\
\hline Kentucky & 0.2521 & 0.3811 & 0.6242 & 0.3108 & Vermont & 0.0000 & 0.1463 & 0.0000 & 0.1611 \\
\hline Louisiana & 0.0000 & 0.3066 & 0.3709 & 0.4187 & Virginia & 0.0000 & 0.0454 & 0.9424 & 0.1321 \\
\hline Maine & 0.1155 & 0.1360 & 0.8495 & 0.4628 & Washington & 0.1086 & 0.0000 & 0.4808 & 0.1218 \\
\hline Maryland & 0.0814 & 0.0000 & 0.2610 & 0.0000 & West Virginia & 0.0000 & 0.0000 & 0.0000 & 0.0000 \\
\hline Massachusetts & 0.0013 & 0.0000 & 0.1123 & 0.0000 & Wisconsin & 0.2290 & 0.2689 & 0.5851 & 0.3319 \\
\hline Michigan & 0.2632 & 0.3929 & 0.0000 & 0.2448 & Wyoming & 0.0000 & 0.0000 & 0.0000 & 0.7937 \\
\hline Minnesota & 0.0987 & 0.1575 & 0.2242 & 0.4284 & Mean & 0.1085 & 0.1180 & 0.3317 & 0.2054 \\
\hline Mississippi & 0.2662 & 0.0000 & 0.8906 & 0.6643 & $S t d$ & 0.1257 & 0.1459 & 0.3309 & 0.2291 \\
\hline Missouri & 0.2496 & 0.3412 & 0.4936 & 0.4470 & Min & 0.0000 & 0.0000 & 0.0000 & 0.0000 \\
\hline Montana & 0.0000 & 0.4197 & 0.9144 & 0.6882 & $\operatorname{Max}$ & 0.4254 & 0.4618 & 0.9424 & 0.7937 \\
\hline Nebraska & 0.1184 & 0.0000 & 0.1954 & 0.0000 & & & & & \\
\hline Nevada & 0.0746 & 0.0001 & 0.1849 & 0.0000 & & & & & \\
\hline
\end{tabular}


Figure 1: Kernel density functions of regional environmental inefficiency estimates using Gaussian Kernel

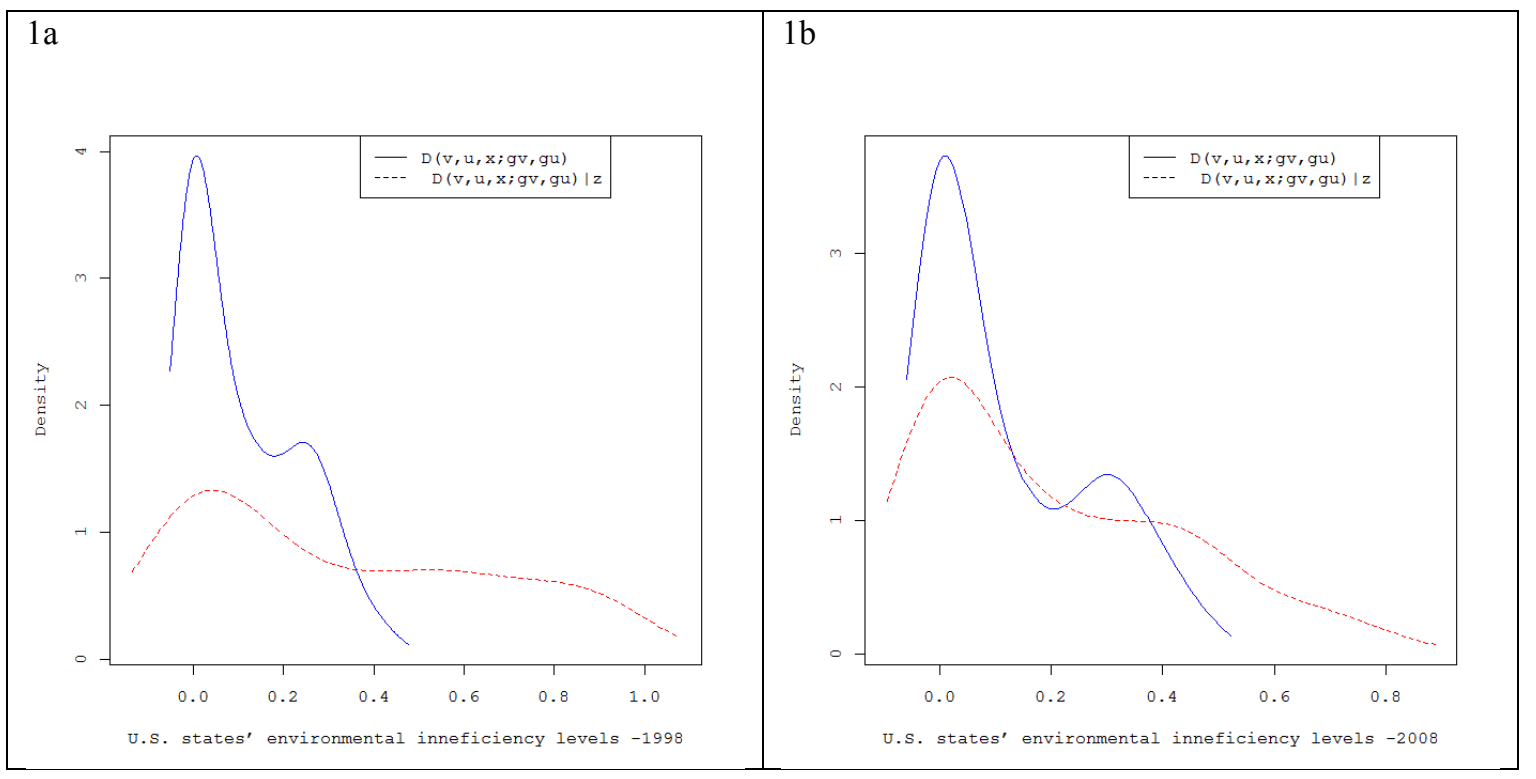


Figure 2: The effect of GDPPC and population on environmental inefficiency levels

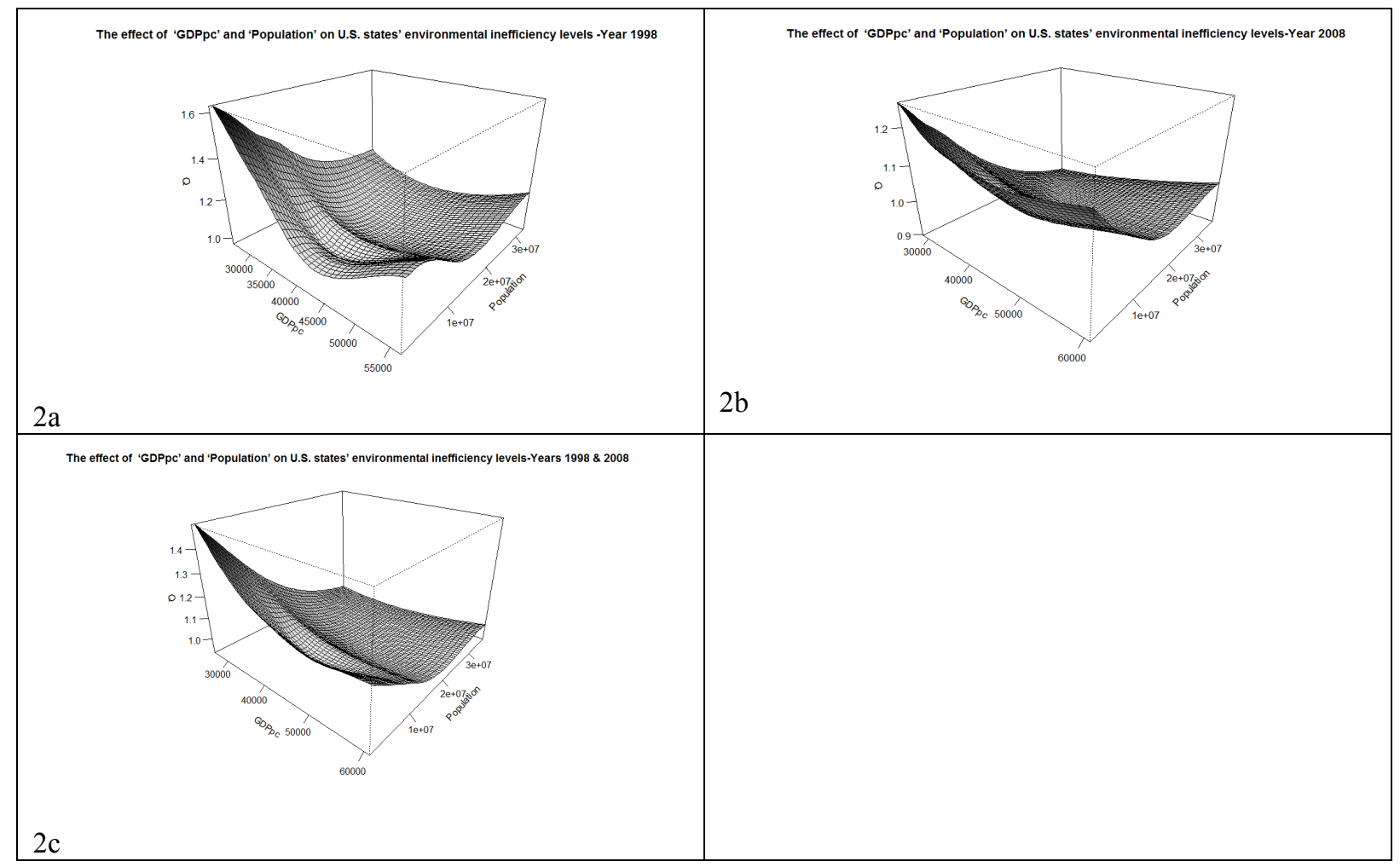


